\title{
Straightforward Proofs of Ostrowski Inequality and Some Related Results
}

\author{
Ghulam Farid \\ COMSATS Institute of Information Technology, Attock Campus, Attock, Pakistan \\ Correspondence should be addressed to Ghulam Farid; faridphdsms@hotmail.com \\ Received 19 July 2016; Accepted 25 October 2016 \\ Academic Editor: Lianwen Wang \\ Copyright (C) 2016 Ghulam Farid. This is an open access article distributed under the Creative Commons Attribution License, which \\ permits unrestricted use, distribution, and reproduction in any medium, provided the original work is properly cited.
}

We give proofs of some known results in very simple and antique way. Also we find some general bounds of a nonnegative difference of the Hadamard inequality and an Ostrowski-Grüss type inequality is proved.

\section{Introduction}

A function $f$ is convex on an interval $[a, b]$ if for all $x_{1}, x_{2} \in$ $[a, b]$ where $0 \leq \lambda \leq 1$,

$$
f\left(\lambda x_{1}+(1-\lambda) x_{2}\right) \leq \lambda f\left(x_{1}\right)+(1-\lambda) f\left(x_{2}\right) .
$$

The most classical result for convex functions can be seen in the following theorem.

Theorem 1. Let $f: I \rightarrow \mathbb{R}$ be a convex function defined on the interval I of real numbers and $a, b \in I$ with $a<b$. Then following double inequality

$$
f\left(\frac{a+b}{2}\right) \leq \frac{1}{b-a} \int_{a}^{b} f(x) d x \leq \frac{f(a)+f(b)}{2}
$$

holds.

It is known as the Hadamard inequality. History of this inequality begins with the papers of Hermite [1] and Hadamard [2] in the years 1883-1893 (see [3]). A rich literature of mathematical inequalities is due to convex functions equally determined by the Hadamard inequality, inspired from this inequality many closely related results have been established which have their applications in approximately all fields of mathematical analysis up to some extent (see, [3-8]).

In 1935 Grüss proved an inequality well known as the Grüss inequality stated in the following theorem [9].
Theorem 2. Let $f, g:[a, b] \rightarrow \mathbb{R}$ be integrable functions such that $\phi \leq f(x) \leq \Phi$ and $\gamma \leq g(x) \leq \Gamma$ for all $x \in[a, b]$, where $\phi, \Phi, \gamma, \Gamma$ are constants. Then we have

$$
\begin{gathered}
\mid \frac{1}{b-a} \int_{a}^{b} f(x) g(x) d x-\frac{1}{b-a} \int_{a}^{b} f(x) d x \\
\cdot \frac{1}{b-a} \int_{a}^{b} g(x) d x \mid \leq \frac{1}{4}(\Phi-\phi)(\Gamma-\gamma),
\end{gathered}
$$

where the constant $1 / 4$ is sharp.

In 1938, Ostrowski established the following inequality known as the Ostrowski inequality stated.

Theorem 3. Let $f: I \rightarrow \mathbb{R}$, where $I$ is an interval in $\mathbb{R}$, be a mapping differentiable in $I^{o}$ the interior of $I$ and $a, b \in I^{o}$, $a<b$. If $\left|f^{\prime}(t)\right| \leq M$, for all $t \in[a, b]$, then we have

$$
\begin{aligned}
\left|f(x)-\frac{1}{b-a} \int_{a}^{b} f(t) d t\right| \\
\quad \leq\left[\frac{1}{4}+\frac{(x-(a+b) / 2)^{2}}{(b-a)^{2}}\right](b-a) M,
\end{aligned}
$$

for all $x \in[a, b]$.

By using Grüss inequality some results have been established which are well known as Ostrowski-Grüss or Ostrowski-Grüss type inequalities (see [10-12] and references 
therein). Several quadrature rules of numerical integration have been estimated using Ostrowski and Ostrowski-Grüss type inequalities (see $[4,5,8,10,12]$ ).

In [4] Cerone and Dragomir have estimated differences of the Hadamard inequality as follows.

Theorem 4. Suppose that $f:[a, b] \rightarrow \mathbb{R}$ be a twice differentiable function on $(a, b)$ and suppose that $\gamma \leq f^{\prime \prime}(t) \leq \Gamma$ for all $t \in(a, b)$. Then we have the double inequality:

$$
\begin{aligned}
\frac{\gamma(b-a)^{2}}{24} & \leq \frac{1}{b-a} \int_{a}^{b} f(t) d t-f\left(\frac{a+b}{2}\right) \\
& \leq \frac{\Gamma(b-a)^{2}}{24} .
\end{aligned}
$$

Theorem 5. Under the assumptions of Theorem 4 we have

$$
\begin{aligned}
\frac{\gamma(b-a)^{2}}{12} & \leq \frac{f(a)+f(b)}{2}-\frac{1}{b-a} \int_{a}^{b} f(t) d t \\
& \leq \frac{\Gamma(b-a)^{2}}{12} .
\end{aligned}
$$

Ujević in [8] also estimated differences of the Hadamard inequality.

Theorem 6. Suppose that $f:[a, b] \rightarrow \mathbb{R}$ be a twice differentiable function on $(a, b)$ and suppose that $\gamma \leq f^{\prime \prime}(t) \leq \Gamma$ for all $t \in(a, b)$. Then we have

$$
\begin{aligned}
\frac{3 S-2 \Gamma}{24}(b-a)^{2} & \leq \frac{1}{b-a} \int_{a}^{b} f(t) d t-f\left(\frac{a+b}{2}\right) \\
& \leq \frac{3 S-2 \gamma}{24}(b-a)^{2},
\end{aligned}
$$

where $S=\left(f^{\prime}(b)-f^{\prime}(a)\right) /(b-a)$.

Theorem 7. Under the assumptions of Theorem 6 we have

$$
\begin{aligned}
\frac{3 S-\Gamma}{24}(b-a)^{2} & \leq \frac{f(a)+f(b)}{2}-\frac{1}{b-a} \int_{a}^{b} f(t) d t \\
& \leq \frac{3 S-\gamma}{24}(b-a)^{2},
\end{aligned}
$$

where $S=\left(f^{\prime}(b)-f^{\prime}(a)\right) /(b-a)$.

The aim of this paper is in fact to establish proof of well known Ostrowski inequality in a very straightforward way, and to establish bounds of a difference of the Hadamard inequality given in $[4,8]$ in very simple way, here there is no need to define a two variable kernel. In the last by involving a parameter a similar but general result have been found and some particular bounds of a difference of the Hadamard inequality are calculated, also an Ostrowski-Grüss type inequality is obtained by elementary calculation.

\section{Some Alternative Proofs}

First we give a proof of well-known Ostrowski inequality, and then proofs of Theorems 4 and 7 are given.

\subsection{Proof of Theorem 3}

Proof. It is clear that

$$
\begin{aligned}
(t-a)\left(f^{\prime}(t)+M\right) & \geq 0, \\
\int_{a}^{x}(t-a)\left(f^{\prime}(t)+M\right) d t & \geq 0 .
\end{aligned}
$$

Integrating by parts we have

$$
(x-a) f(x)-\int_{a}^{x} f(t) d t+\frac{M}{2}(x-a)^{2} \geq 0 .
$$

Also

$$
(b-t)\left(M-f^{\prime}(t)\right) \geq 0,
$$

$$
\int_{x}^{b}(b-t)\left(M-f^{\prime}(t)\right) d t \geq 0 .
$$

Integrating by parts we have

$$
(b-x) f(x)-\int_{x}^{b} f(t) d t+\frac{M}{2}(b-x)^{2} \geq 0 .
$$

By adding (10) and (12) one has

$$
\begin{aligned}
& f(x)-\frac{1}{b-a} \int_{a}^{b} f(t) d t \\
& \geq-\frac{M}{2(b-a)}(x-a)^{2}+(x-b)^{2} .
\end{aligned}
$$

On the other hand using positivity of $(b-t)\left(f^{\prime}(t)+M\right)$ and $(t-a)\left(M-f^{\prime}(t)\right)$ we have

$$
\begin{aligned}
\int_{a}^{x}(t-a)\left(M-f^{\prime}(t)\right) d t \\
\quad+\int_{x}^{b}(b-t)\left(M+f^{\prime}(t)\right) d t \geq 0 .
\end{aligned}
$$

From which one can have

$$
\begin{aligned}
& f(x)-\frac{1}{b-a} \int_{a}^{b} f(t) d t \\
& \quad \leq \frac{M}{2(b-a)}(x-a)^{2}+(x-b)^{2} .
\end{aligned}
$$

From inequalities in (13) and (15) we have

$$
\begin{aligned}
& \left|f(x)-\frac{1}{b-a} \int_{a}^{b} f(t) d t\right| \\
& \quad \leq \frac{M}{2(b-a)}\left((x-a)^{2}+(x-b)^{2}\right) .
\end{aligned}
$$

Using the following identity one can get inequality in (4)

$$
\begin{aligned}
(x-a)^{2}+(x-b)^{2} & \\
& =2(b-a)^{2}\left[\frac{1}{4}+\frac{(x-(a+b) / 2)^{2}}{(b-a)^{2}}\right] .
\end{aligned}
$$




\subsection{Proof of Theorem 4}

Proof. It is clear that

$$
\begin{array}{r}
(t-a)^{2}\left(f^{\prime \prime}(t)-\gamma\right) \geq 0 \\
\int_{a}^{(a+b) / 2}(t-a)^{2}\left(f^{\prime \prime}(t)-\gamma\right) d t \geq 0 .
\end{array}
$$

Integrating by parts we have

$$
\begin{gathered}
\left(\frac{b-a}{2}\right)^{2} f^{\prime}\left(\frac{a+b}{2}\right)-(b-a) f\left(\frac{a+b}{2}\right) \\
+2 \int_{a}^{(a+b) / 2} f(t) d t-\frac{(b-a)^{3} \gamma}{24} \geq 0 .
\end{gathered}
$$

Now using $(t-b)^{2}\left(f^{\prime \prime}(t)-\gamma\right) \geq 0$ and integrating on $[(a+$ b) $/ 2, b]$ we have

$$
\begin{gathered}
-\left(\frac{b-a}{2}\right)^{2} f^{\prime}\left(\frac{a+b}{2}\right)-(b-a) f\left(\frac{a+b}{2}\right) \\
+2 \int_{(a+b) / 2}^{b} f(t) d t-\frac{(b-a)^{3} \gamma}{24} \geq 0 .
\end{gathered}
$$

Adding (19) and (20) one can have

$$
\frac{1}{b-a} \int_{a}^{b} f(t) d t-f\left(\frac{a+b}{2}\right) \geq \frac{(b-a)^{2} \gamma}{24} .
$$

Similarly using $(t-a)^{2}\left(\Gamma-f^{\prime \prime}(t)\right) \geq 0$ and integrating on $[a,(a+b) / 2]$ we have

$$
\begin{gathered}
-\left(\frac{b-a}{2}\right)^{2} f^{\prime}\left(\frac{a+b}{2}\right)+(b-a) f\left(\frac{a+b}{2}\right) \\
-2 \int_{a}^{(a+b) / 2} f(t) d t+\frac{(b-a)^{3} \Gamma}{24} \geq 0 .
\end{gathered}
$$

Now using $(t-b)^{2}\left(\Gamma-f^{\prime \prime}(t)\right) \geq 0$, integrating on $[(a+b) / 2, b]$ we have

$$
\begin{gathered}
\left(\frac{b-a}{2}\right)^{2} f^{\prime}\left(\frac{a+b}{2}\right)+(b-a) f\left(\frac{a+b}{2}\right) \\
-2 \int_{(a+b) / 2}^{b} f(t) d t+\frac{(b-a)^{3} \Gamma}{24} \geq 0 .
\end{gathered}
$$

Adding (22) and (23) we have

$$
\frac{1}{b-a} \int_{a}^{b} f(t) d t-f\left(\frac{a+b}{2}\right) \leq \frac{(b-a)^{2} \Gamma}{24} .
$$

From (21) and (24) we have (5).

\subsection{Proof of Theorem 7}

Proof. It is clear that

$$
\begin{array}{r}
\left(t-\frac{a+b}{2}\right)^{2}\left(f^{\prime \prime}(t)-\gamma\right) \geq 0, \\
\int_{a}^{b}\left(t-\frac{a+b}{2}\right)^{2}\left(f^{\prime \prime}(t)-\gamma\right) \geq 0 .
\end{array}
$$

Integrating by parts we have

$$
\frac{f(a)+f(b)}{2}-\frac{1}{b-a} \int_{a}^{b} f(t) d t \leq \frac{(b-a)^{2}(3 S-\gamma)}{24} .
$$

Similarly using $(t-(a+b) / 2)^{2}\left(\Gamma-f^{\prime \prime}(t)\right) \geq 0$ and integrating on $[a, b]$ we have

$$
\frac{f(a)+f(b)}{2}-\frac{1}{b-a} \int_{a}^{b} f(t) d t \geq \frac{(b-a)^{2}(3 S-\Gamma)}{24} .
$$

From (26) and (27) we have (8).

\section{Some Related Results}

In this section we give some more results in a very simple way. First by involving a parameter, we prove a general result that provides bounds of a nonnegative difference of the Hadamard inequality and gives particular bounds, and then an Ostrowski-Grüss type inequality is proved.

Theorem 8. Suppose that $f:[a, b] \rightarrow \mathbb{R}$ be a twice differentiable function on $(a, b)$ and suppose that $\gamma \leq f^{\prime \prime}(t) \leq \Gamma$ for all $t \in(a, b)$. Then we have

$$
\begin{aligned}
& \frac{(24+\alpha) \gamma-24 S}{24 \alpha}(b-a)^{2} \\
& \leq \frac{1}{b-a} \int_{a}^{b} f(t) d t-f\left(\frac{a+b}{2}\right) \\
& \leq \frac{(24+\alpha) \Gamma-24 S}{24 \alpha}(b-a)^{2},
\end{aligned}
$$

where $S=\left(f^{\prime}(b)-f^{\prime}(a)\right) /(b-a)$.

Proof. It is clear that

$$
\int_{a}^{b}\left(f^{\prime \prime}(t)-\gamma\right) d t \geq 0
$$

From which one has

$$
\frac{f^{\prime}(b)-f^{\prime}(a)}{b-a}(b-a)-\gamma(b-a) \geq 0 .
$$

Further we can say for some $\alpha>0$

$$
\frac{S-\gamma}{\alpha}(b-a)^{2} \geq 0
$$

Adding (21) and (31) one has

$$
\begin{gathered}
\frac{1}{b-a} \int_{a}^{b} f(t) d t-f\left(\frac{a+b}{2}\right) \\
\geq \frac{(24+\alpha) \gamma-24 S}{24 \alpha}(b-a)^{2} .
\end{gathered}
$$

On the other hand $\int_{a}^{b}\left(\Gamma-f^{\prime \prime}(t)\right) d t \geq 0$, which gives for $\alpha>0$

$$
\frac{S-\Gamma}{\alpha}(b-a)^{2} \leq 0 .
$$


Adding (24) and (33) one has

$$
\begin{gathered}
\frac{1}{b-a} \int_{a}^{b} f(t) d t-f\left(\frac{a+b}{2}\right) \\
\leq \frac{(24+\alpha) \Gamma-24 S}{24 \alpha}(b-a)^{2} .
\end{gathered}
$$

From (32) and (34) we have the required inequality.

Corollary 9. If one selects, for example, $\alpha=24$ and $\alpha=48$ in Theorem 8, then

$$
\begin{aligned}
\frac{2 \gamma-S}{24}(b-a)^{2} & \leq \frac{1}{b-a} \int_{a}^{b} f(t) d t-f\left(\frac{a+b}{2}\right) \\
& \leq \frac{2 \Gamma-S}{24}(b-a)^{2}, \\
\frac{3 \gamma-S}{48}(b-a)^{2} & \leq \frac{1}{b-a} \int_{a}^{b} f(t) d t-f\left(\frac{a+b}{2}\right) \\
& \leq \frac{3 \Gamma-S}{48}(b-a)^{2} .
\end{aligned}
$$

In the following, adopting the pattern of proofs we give the following Ostrowski-Grüss type inequality. It is remarkable to mention here that in [11] Cheng has proved an improved result adopting a comparatively different method.

Theorem 10. Let $f:[a, b] \rightarrow \mathbb{R}$, where $I$ is an interval in $\mathbb{R}$ be a mapping differentiable in $I^{o}$, the interior of $I$ and $a, b \in I^{o}$, $a<b$. If $\gamma \leq f^{\prime}(t) \leq \Gamma$ for all $t \in(a, b)$, then we have

$$
\begin{aligned}
& \mid \frac{1}{2} f(x)-\frac{(x-b) f(b)-(x-a) f(a)}{2(b-a)} \\
& \quad-\frac{1}{b-a} \int_{a}^{b} f(t) d t \mid \leq \frac{(x-a)^{2}+(b-x)^{2}}{4(b-a)}(\Gamma-\gamma),
\end{aligned}
$$

for all $x \in[a, b]$.

Proof. It is clear that $(x-t)\left(f^{\prime}(t)-\gamma\right) \geq 0$ and $(t-a)(\Gamma-$ $\left.f^{\prime}(t)\right) \geq 0$ for all $t \in[a, x]$. Therefore

$$
\begin{aligned}
& \int_{a}^{x}(x-t)\left(f^{\prime}(t)-\gamma\right) d t+\int_{a}^{x}(t-a)\left(\Gamma-f^{\prime}(t)\right) d t \\
& \quad \geq 0 .
\end{aligned}
$$

After some computation we have

$$
\begin{aligned}
& (x-a) f(x)+(x-a) f(a)-2 \int_{a}^{x} f(t) d t \\
& \leq \frac{1}{2}(x-a)^{2}(\Gamma-\gamma) .
\end{aligned}
$$

Also it is easy to see $(t-x)\left(\Gamma-f^{\prime}(t)\right) \geq 0$ and $(b-t)\left(f^{\prime}(t)-\gamma\right) \geq$ 0 for all $t \in[x, b]$. Therefore

$$
\int_{x}^{b}(t-x)\left(\Gamma-f^{\prime}(t)\right) d t+\int_{x}^{b}(b-t)\left(f^{\prime}(t)-\gamma\right) d t
$$

$$
\geq 0 \text {. }
$$

After some computation it can be seen

$$
\begin{aligned}
& (b-x) f(x)-(x-b) f(b)-2 \int_{x}^{b} f(t) d t \\
& \quad \leq \frac{1}{2}(b-x)^{2}(\Gamma-\gamma) .
\end{aligned}
$$

By adding (38) and (40) one has

$$
\begin{aligned}
\frac{1}{2} f(x) & -\frac{(x-b) f(b)-(x-a) f(a)}{2(b-a)} \\
& -\frac{1}{b-a} \int_{a}^{b} f(t) d t \\
\leq & \frac{(x-a)^{2}+(b-x)^{2}}{4(b-a)}(\Gamma-\gamma) .
\end{aligned}
$$

On the other hand we have

$$
\begin{aligned}
& \int_{a}^{x}(t-a)\left(f^{\prime}(t)-\gamma\right) d t+\int_{a}^{x}(x-t)\left(\Gamma-f^{\prime}(t)\right) d t \\
& \quad \geq 0 ; \quad t \in[a, x] .
\end{aligned}
$$

This gives

$$
\begin{aligned}
& (x-a) f(x)+(x-a) f(a)-2 \int_{a}^{x} f(t) d t \\
& \geq-\frac{1}{2}(x-a)^{2}(\Gamma-\gamma) .
\end{aligned}
$$

Also we have

$$
\begin{aligned}
& \int_{x}^{b}(b-t)\left(\Gamma-f^{\prime}(t)\right) d t+\int_{x}^{b}(t-x)\left(f^{\prime}(t)-\gamma\right) d t \\
& \quad \geq 0 ; \quad t \in[x, b]
\end{aligned}
$$

which gives

$$
\begin{aligned}
& (b-x) f(x)-(x-b) f(b)-2 \int_{x}^{b} f(t) d t \\
& \geq-\frac{1}{2}(b-x)^{2}(\Gamma-\gamma) .
\end{aligned}
$$

Adding (43) and (45), then combining with (41) one can get (36).

\section{Competing Interests}

The author declares that there is no conflict of interests regarding the publication of this paper.

\section{References}

[1] C. Hermite, "Sur deux limites dúne intégrale définie," Mathesis, vol. 3, p. 182, 1883.

[2] J. Hadamard, "Etude sur les propriétés des fonctions entières et en particulier d'une fonction considérée par Riemann," Journal de Mathématiques Pures et Appliquées, vol. 58, pp. 171-215, 1893. 
[3] C. P. Niculescu and L. E. Persson, Convex Functions and Their Applications: A Contemporary Approach, vol. 23 of CMS Books in Mathematics, Springer, New York, NY, USA, 2006.

[4] P. Cerone and S. S. Dragomir, "Midpoint-type rules from an inequalities point of view," in Handbook of AnalyticComputational Methods in Applied Mathematics, G. Anastassiou, Ed., pp. 135-200, CRC Press, New York, NY, USA, 2000.

[5] P. Cerone and S. S. Dragomir, "Trapezoidal-type rules from an inequalities point of view," in Handbook of AnalyticComputational Methods in Applied Mathematics, G. Anastassiou, Ed., pp. 65-134, CRC Press, New York, NY, USA, 2000.

[6] S. S. Dragomir, "A mapping in connection to Hadamards inequalities," Oster. Akad. Wiss. Math. Natur, vol. 128, pp. 17-20, 1991.

[7] S. S. Dragomir and C. E. M. Pearce, Selected Topics on HermiteHadamard Inequalities and Applications, RGMIA Monographs, 2000.

[8] N. Ujević, "Some double integral inequalities and applications," Acta Mathematica Universitatis Comenianae. New Series, vol. 71, no. 2, pp. 189-199, 2002.

[9] G. Grüss, "Über das Maximum des absoluten Betrages von $1 / b-a \int_{a}^{b} f(x) g(x) d x-1 /(b-a)^{2} \int_{a}^{b} f(x) d x \int_{a}^{b} g(x) d x, "$ Mathematische Zeitschrift, vol. 39, no. 1, pp. 215-226, 1935.

[10] N. S. Barnett, P. Cerone, S. S. Dragomir, J. Roumeliotis, and A. Sofo, "A survey on Ostrowski type inequalities for twice differentiable mappings and applications," in Inequality Theory and Applications, pp. 24-30, Nova Science Publishers, Huntington, NY, USA, 2001.

[11] X.-L. Cheng, "Improvement of some Ostrowski-Grüss type inequalities," Computers \& Mathematics with Applications, vol. 42, no. 1-2, pp. 109-114, 2001.

[12] S. S. Dragomir and S. Wang, "An inequality of Ostrowski-Grüss' type and its applications to the estimation of error bounds for some special means and for some numerical quadrature rules," Computers \& Mathematics with Applications, vol. 33, no. 11, pp. 15-20, 1997. 


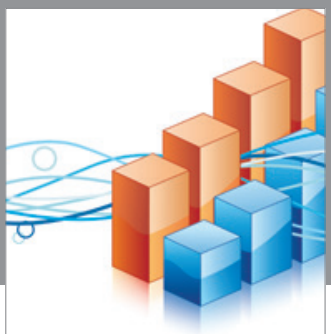

Advances in

Operations Research

vatem alat4

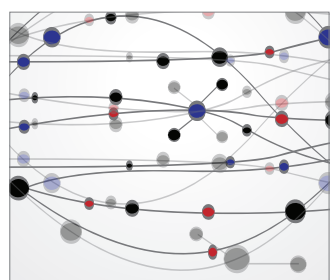

\section{The Scientific} World Journal
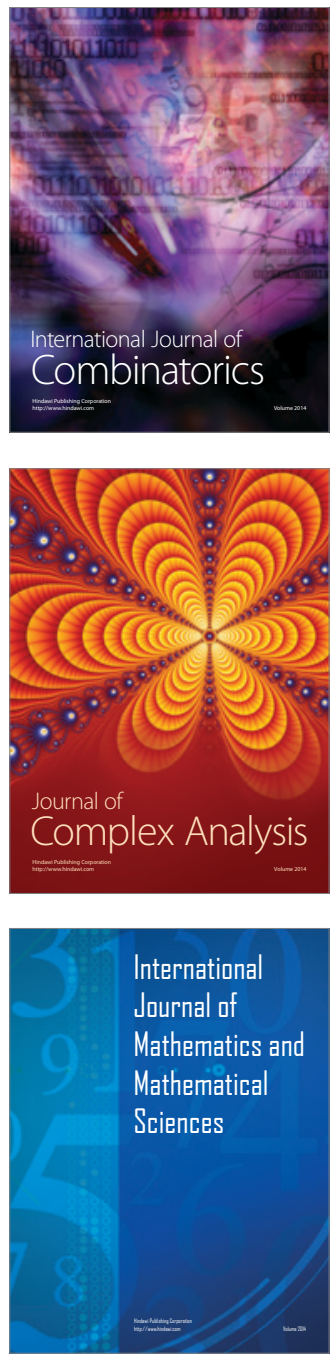
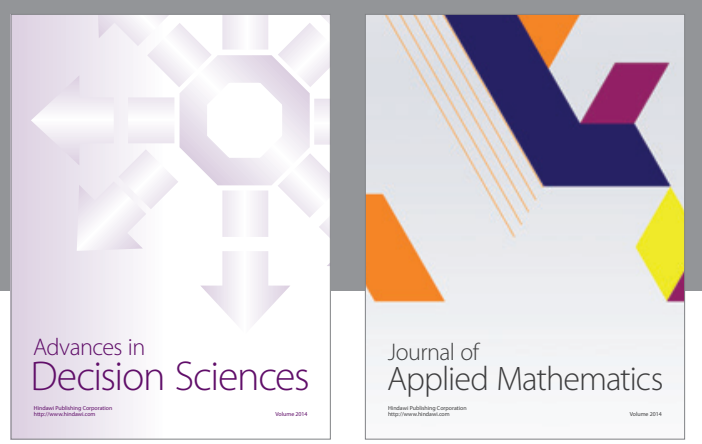

Algebra

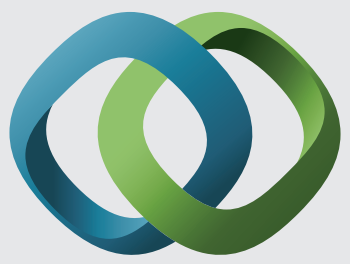

\section{Hindawi}

Submit your manuscripts at

http://www.hindawi.com
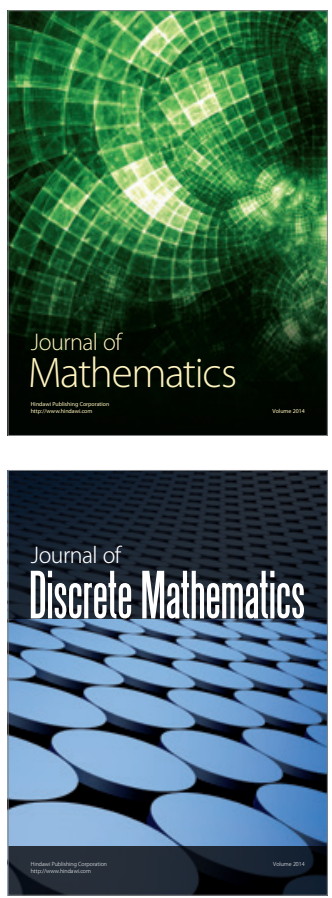

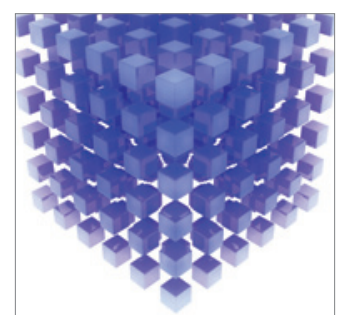

Mathematical Problems in Engineering
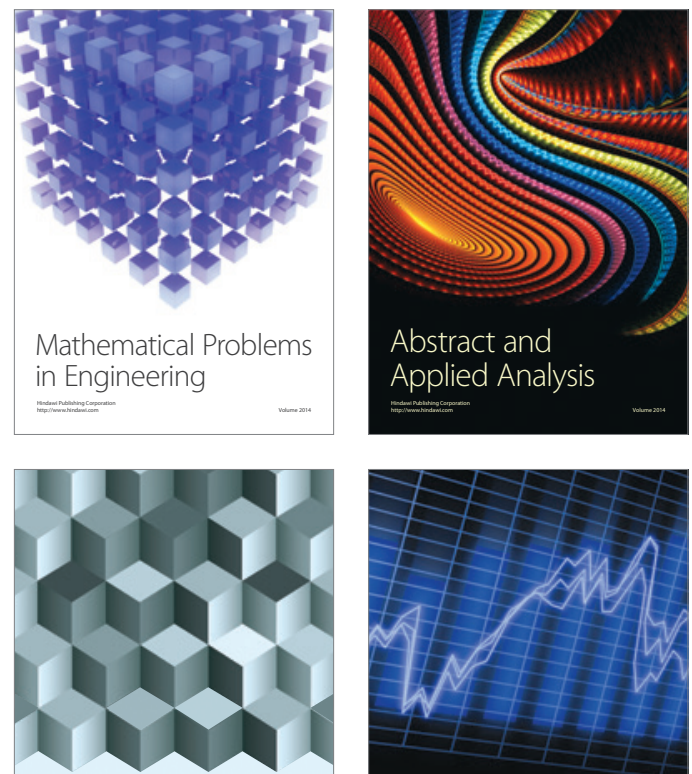

Journal of

Function Spaces

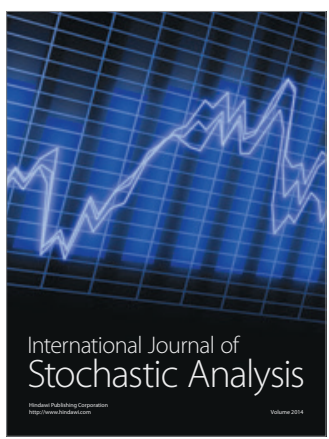

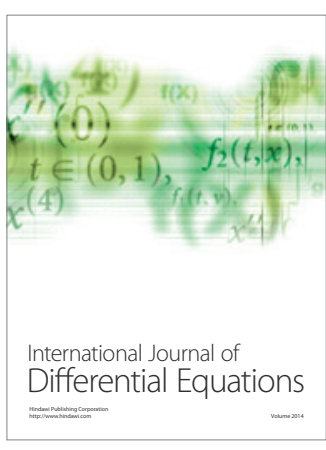
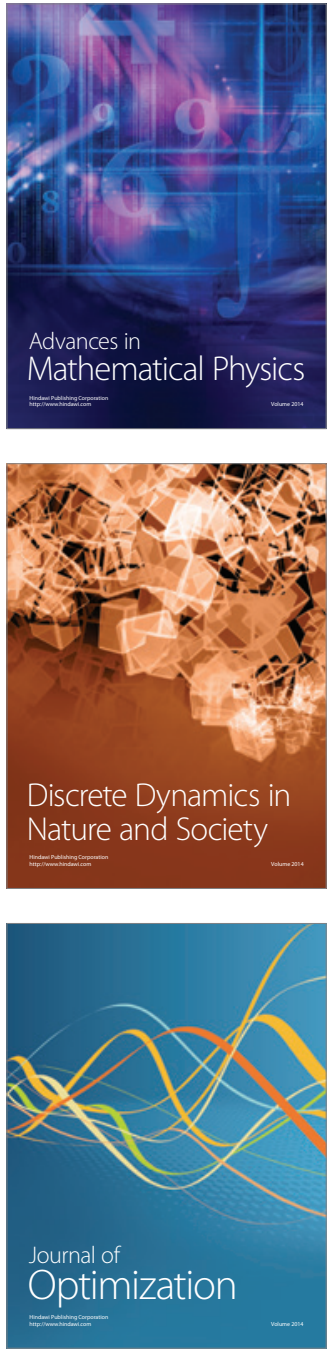